\title{
STUDY ON REFORM OF ELECTRONIC TECHNOLOGY EXPERIMENTAL TEACHING UNDER BACKGROUND OF "NEW ENGINEERING”
}

\author{
Hongtu Xie ${ }^{1}$, Kang Liang ${ }^{1}$, Xinqiao Jiang ${ }^{1}$, Kaipeng Chen ${ }^{1}$, \\ Guoqian Wang, ${ }^{2, *}$ and Kai Xie ${ }^{1, *}$ \\ ${ }^{1}$ School of Electronics and Communication Engineering, \\ Sun Yat-sen University, Guangzhou 510275, China \\ ${ }^{2}$ Sun Yat-sen Memorial Hospital, Sun Yat-sen University, Guangzhou 510120, China
}

\begin{abstract}
To meet the requirements for the cultivating of the high-quality engineering talents for the development of the "new engineering", the college's electronic information majors develop the teaching reforms of the electronic technology experiment based on the overall planning and development of the professional construction, and explore the cultivation of the active learning ability and practical innovation capability of the students under the development of the "new engineering ", which is able to provide the support for cultivating the high-level engineering and scientific talents. This paper explores and reforms the electronic technology experimental teaching from the aspects of the experimental teaching system, teaching content, teaching methods, teaching process, teaching assessment and teacher construction, which can propose the new ideas for the construction of the electronic technology experimental courses adapted to the development of the "new engineering". The proposed teaching reform can further improve the quality and effect of the experimental teaching and improve the students' capability of solving the practical engineering problems, teamwork, technical communication and independent innovation, which explores a new way of the deep chemical engineering experimental teaching reform based on the concept of the "new engineering".
\end{abstract}

\section{KEYWORDS}

Electronic Technology Experiment, Teaching Reform, "New Engineering”, Engineering Talent Training, Practical Innovation Capability.

\section{INTRODUCTION}

In recent years, the new round of the scientific and technological revolution at home and abroad has promoted the vigorous development of the global emerging economy, which has put forward the new requirements for the development of the higher engineering education and the training of the engineering science and technology talents (Hadek et al., 2019; Geng et al., 2020; Barnes et al., 2020; Ntinda1 \& Ngozwana, 2021). Therefore, deepening the reform of the higher engineering education and building a strong country in the higher engineering education has important practical significance for supporting and serving the global economic transformation and upgrading (Lin, 2017; Shang et al., 2019). Since the traditional engineering education is difficult to meet the needs of the emerging economic development for the engineering and technological talents, the education department has begun to vigorously develop and explore the construction and developmemt of the "new engineering", from "Fudan Consensus" (Ministry of Education, 2017a) to the "Tian Da Action" (Ministry of Education, 2017b), and then to the "Beijing Guide" (Ministry of Education, 2017c), pointed out the reform direction and course of 
the action for the higher engineering education under the new situation. Shang et al., (2019) has pointed out "five news", which mainly includes establishing the new concept of the engineering education, constructing the new structure of the disciplines, exploring the new models of the talent training, and establishing the classified development of the new system, and creating the new quality of the education and teaching (Wen, 2021). The proposal of the innovative concept of the "new engineering" has brought forward the new directions and opportunities for the development of the engineering majors and curriculum reforms. It makes the higher requirement for the higher engineering education and cultivation of the engineering science and technology talents, which requires the engineering majors to focus on the training the high-quality talents with the well basic scientific literacy and engineering innovation spirit, solid experimental foundation, high comprehensive experimental quality, and then can be able to engage in the basic and applied research (Shang et al., 2019; Yuan et al., 2019).

The electronic technology course is a compulsory course for the majors in the electronics, communication, automation, computer, intelligent science, which is a professional basic course with the wider applications and stronger practicality (Rohde et al., 2019; Kaloostian \& Chhetri, 2021; Deng, 2016). To fulfil the requirement for the cultivating of the high-quality engineering talents for the development of the "new engineering", the college electronic information majors develop the teaching reform of the electronic technology experiments based on the overall planning and development of the professional construction, and explore the cultivation of the active learning ability and practical innovation ability of the students under the development of the "new engineering", which can provide the support for cultivating the high-level engineering and scientific talents (Kittur, 2020; Passadelli \& Klonari, 2021; Li et al., 2018). Please note that a part work of this research has been published in Xie et al., (2021). This paper can be listed as follows. Section 2 introduces the necessity and importance of the teaching reform of the electronic technology. Then, the strategy of the teaching reform of the electronic technology is proposed form six aspects in Section 3. In Section 4, a case of the teaching reform of the electronic technology is shown and analysed. Section 5 shows the effects and reflection of the teaching reform of the electronic technology. Finally, a conclusion is given in Section 6.

\section{REFORM NECESSITY}

The experimental course teaching is an important way for the schools to implement the higher engineering education and cultivate the practical and innovative ability of the student. Therefore, the laboratory used to carry out the teaching of the experimental courses is an important content of the teaching reform, which can provide the students with the good experimental places and experimental conditions. According to the requirements of implementing the higher engineering education and cultivating the innovative engineering talents, it is necessary to pay the more attention to the experimental teaching, strengthen the practical links, and focus on cultivating the hands-on capability of the student (Rohde et al., 2019; Yang, 2020). Conducting the experimental teaching of the electronic technology is able to enable the students to obtain the experimental verification of the theoretical knowledge they have learned, allow the students to find the problem in the experiment, and then use the theoretical knowledge to analyse and settle the found issue, to reach to the purpose of consolidating theoretical knowledge, thereby training the students' basic practical skills in the electronic technology. At present, there are mainly the following problems in the experimental teaching of the electronic technology (Yang, 2020).

\subsection{Limited Experimental Time}

Each experimental teaching time is relatively limited (is usually two class hours), if the experimental content is more or more difficult, sometimes it is difficult to complete within the 
limited time. Therefore, it is necessary to choose easier experiments or simplified experiments, so that it is very difficult for the student to fully understand and grasp the theoretical knowledge.

\subsection{Confirmatory Experimental Task}

The experiments carried out are mainly confirmatory, in which the content and procedures of the experiments are basically determined, therefore there is a lack of the self-designed links. Therefore, although the confirmatory experiments can make it easy for the students to master the theoretical knowledge they have learned, it is very difficult to cultivate the students' ability to discover, analyse and solve the existing issues.

\subsection{Non-innovative Experimental Content}

The experimental teaching of the electronic technology course is generally based on the theoretical teaching of the electronic technology course, and the corresponding experimental content is often selected by the teacher of the theoretical teaching, which may lead to the lack of the innovation in the experimental content and it is difficult to exert the subjective initiative.

\subsection{Experimental Venues with Different Conditions}

The different universities have the different investments in the construction of the experimental teaching, resulting in the large differences in the experimental sites and conditions. If the experimental sites and conditions are not perfect, and there are many students who carry out the experimental teaching, it is difficult to carry out the single-person experiments, and only the groups of the multiple people can carry out the experiments, which makes it very difficult to cultivate the independent thinking and practical capability of the students (Wang et al., 2020).

\subsection{Less Open Experimental Teaching}

Although the Ministry of Education has emphasized the active development of the openly experimental teaching, only a few strong universities have built the open experiments and can carry out the open experimental teaching tasks. Due to the various reasons, most colleges and universities are unable to truly implement the open experimental teaching tasks, which makes it very difficult to cultivate the innovative and practical abilities of the student (Wang et al., 2020). To further fulfil the requirement of the "new engineering" for the development of the higher engineering education and the cultivating of the engineering science and technology talents, it is very necessary to strengthen the combination of the theoretical teaching and practical teaching, to give play to subjective initiative of the students and cultivate the practical capability and innovative spirit of the students. The electronic technology courses are the basic professional courses for the development of the "new engineering", which can lay the solid theoretical and practical foundation for the subsequent professional courses. Therefore, it is very necessary to vigorously carry out the study on the experimental teaching reform of the electronic technology course adapted to the development of the "new engineering".

\section{REFORM STRATEGY}

Based on the analysis of the existing problems of the experimental teaching of the electronic technology course, and according to the new requirements of the development of the "new engineering" for the experimental teaching, the research on the reform of the experimental teaching of the electronic technology course has been carried out, so as to cultivate the highquality engineering and technical talents adapted to the development of the "new engineering". 
The experimental teaching reform content mainly includes rebuilding the experimental teaching systems, updating the experimental teaching contents, reforming the experimental teaching methods, innovating and organizing the experimental teaching processes, establishing the diversified experimental assessment methods and optimizing the knowledge structure of the experimental teachers of the electronic technology course.

\subsection{Rebuild the Experimental Teaching System}

Rebuilding the experimental teaching system is the first task of carrying out the reform of the experimental teaching of the electronic technology course. The experimental content of the electronic technology course can be set to four levels, which includes the basic skills level, comprehensive design level, innovative practice level, and science and technology research level. The basic skill level experiment is mainly used to cultivate the students' basic knowledge and skills of the electronic technology, such as the experiment of using the instruments, experiment of operating the instruments, etc. The comprehensive design level experiment is mainly used to cultivate the students' synthesis and design ability of the electronic technology, such as the design experiment of the single-tube amplifier circuit, design experiment of the combinational logic circuit, design experiment of the power amplifier, etc. The innovation practice level experiment is mainly used to cultivate the students' innovation and practical ability of the electronic technology, such as the digital electronic clock experiment, competition answerer experiment, and the signal transmitter experiment, etc. The innovation practice level experiment is based on the comprehensive design level experiment to further cultivate the comprehensive application ability and innovation capability of the students, which can lay a practical foundation for the engaging in the engineering project research. The science and technology research level experiments are mainly used to cultivate the engineering practice and research capability of the students, such as the scientific research projects, subject competitions and graduation projects, so that the interested students have the opportunity to join the scientific research team to carry out the scientific and technological research. Though optimizing the experimental teaching of the electronic technology, and constructing the distinct experimental course module, thus a systematic, comprehensive, hierarchical and modular system of the electronic technology experimental teaching has been formed.

\subsection{Update Experimental Teaching Content}

At present, the teaching content mainly carries out the verification and simulation experiments, and lacks the open and innovative experiments, so the experimental teaching content may be relatively single. In addition, ignoring the establishment of the experimental teaching between the cross-curricular courses, and ignoring the development of the related experimental teaching such as the scientific research projects and subject competitions, it is very difficult to improve the engineering innovation and practical ability of the students, therefore it cannot satisfy the development of the "new engineering" for the cultivating requirements of the high-quality engineering and technical talents.

When choosing the experimental teaching content, we should pay the important attention to the combination characteristic of the practicality, cutting-edge and engineering. The experimental teaching content of the electronic technology course should fulfil the requirements of the times development, the requirements of the subject development and the requirement of the talent cultivating, which thereby fulfils the objective requirements of adapting to the development of the "new engineering". It should meet the requirements of the emerging economy and "new engineering" for the innovative scientific and technological talents and meet the requirements of the emerging industries and emerging economy for the high-quality compound talents, thereby promoting the development of the times. It should also meet the requirements of the new 
electronic technology applications for the electronic technology and meet the requirements of the development of the new electronic technology for the professional and technical personnel, thereby promoting the development of the disciplines. It should meet the requirements of the talent cultivating for the individuality and diversified experimental teaching methods and meet the requirements of the subject development for the experimental teaching content and method innovation, thereby realizing the cultivating of the talents (Yang, 2020). Thus, we can consider improving from the following aspects.

\subsubsection{Advanced technology enters the experimental teaching}

In the teaching process, the teachers should master the current development and technological frontiers of the electronic technology, introduce the advanced technologies into the experimental teaching, and allow the students to keep the track of the latest progresses and development trends of the electronic technology in time. Thus, actively introducing the status and advantages of the modern electronic technology in the teaching process can further develop the students' subjective initiative based on the learning and understanding the new electronic technology, which can cultivate the students' design and practical capability of the electronic technology.

\subsubsection{Scientific research and academic achievement enter the experimental teaching}

The teachers in the colleges and universities usually preside over or undertake the scientific research projects, and then engage in the related scientific research and academic research, thus introducing the scientific research academic achievements into the experimental teaching courses can extract the experimental teaching content related to the electronic technology. Thus, the integration of the scientific research and academic achievements into the experimental teaching can further deepen the understanding and grasping of the theoretical knowledge, which can realize the perfect combination of the experiment and theory, and then further cultivate the comprehensive analysis ability and electronic design capability of the students.

\subsubsection{Develop the new model of the industry-university-research cooperation}

The trained students in the "new engineering" mainly meet the requirements of the enterprises for high-quality engineering and scientific talents. The new model of the industry-university-research cooperation with the enterprises is able to provide the students with the appropriate opportunities and places for the scientific and technological research and the engineering project research and development, which is able to cultivate the students' ability to apply the theoretical knowledge, and strengthen the students' capability in the scientific research, teamwork, and management service. Through the development of the new model of the industry-university-research cooperation, the trained students can better meet the requirements of the enterprises for the engineering practice capabilities.

\subsection{Reform Experimental Teaching Method}

The fourth of the "Tianda Action" is to "Asking the students' aspirations to change the methods and innovate the engineering education methods" (Ministry of Education, 2017b). Thus, the experimental teaching should be student-cantered, and reform the teaching methods according to the interests of the students, enhance the autonomy and selectivity of the students, give full play to the subjective initiative of the students, and stimulate the passion of the students for the handson practice, which can cultivate the students' well interests and hobbies and the strong practical capability (Leung et al., 2021). According to the features of the teaching content and teaching purpose, the diversified experimental teaching methods can be used to meet the needs of the development of the "new engineering". 
(1) With the help of the modern teaching technology and virtual simulation methods, and the application of the network shared resources (such as the MOOC, micro-class, video class and live class, etc.), the comprehensive laboratory, innovation practice laboratory, virtual simulation laboratory, and intelligence shared laboratory of the electronic technology course can be built, which can combine the virtual simulation experiments with the on-site practical experiments, so as to mobilize the students' enthusiasm and improve the effect of the experimental teaching. (2) Applying the new multimedia technology to teach and demonstrate the experimental teaching content, through the flexible and diverse animation videos, is able to increase the interest of the teaching content and achieve the good teaching results. (3) Using the online webcast to conduct the experimental teaching of the courses can interact and communicate with the students vividly, enhance the interest of the students in the learning, and then improve the teaching effects (Geng, 2020). (4) Establishing a teacher-student exchange group, through the communication with the students and the discussion of the problems encountered in the experiment, which can exercise students' capability to discover, analyse and solve the problems, and achieve the purpose of the paying close attention to their learning dynamically. (5) For the large-scale comprehensive experimental teaching of the electronic technology, through the introduction of the scientific research projects, subject competitions, etc., it can cultivate the students' innovative thinking in the scientific research and improve the capability of the independent thinking and scientific research (Lalos \& Skarpa, 2020).

\subsection{Innovative Organization of Experimental Teaching Process}

According to the innovative concept of the "new engineering" development, the experimental teaching process needs to be transformed from the knowledge transferring to the problem solving and ability training. Before the start of the experiment, let students preview the content of the experiment in the advance, query the related materials according to the purposes and requirements of the experiment, design the experiment plan independently by a group or team, conduct the discussion and exchange, and modify the plan. During the experiments, the students are required to connect the components and build the circuits based on the functions of the experimental circuit. For the circuit failures or measurement problems that appear in the experiment, the students can be allowed to find the causes and troubleshoot the failures by themselves while ensuring the safety, which can cultivate the capability to discover, analyse and solve the problems, and improve the innovative and practical ability of the students. After the experiment, the students should summarize and analyse the designed plan of the experiments, experimental operation process, and experimental measurement results (Yang, 2020).

In addition, for the large-scale comprehensive experimental teaching, the groups or teams should independently design the experimental plans, build the experimental circuits, carry out the experimental measurements, and make the analysis of the experimental results, conduct the discussion, questioning and exchanges, which can cultivate the practical innovation capability and the teamwork ability of the students (Duarte et al., 2020). The specific experimental process mainly includes the determining the experimental tasks, designing the experimental schemes, building and debugging the experimental circuits, measuring the experimental results and then writing the experimental reports, finally checking the experimental effect. The specific process includes: (1) Determining the experimental task. According to the knowledge level and practical capability of the students, the experimental task is determined. 2-4 students form a group, and the members determine the design the plan through the mutual discussion and inspiration. (2) Designing the experimental schemes. According to the existing experimental conditions, the program should be screened, the sub-tasks are set, and the relevant software is used to complete the design, simulation and verification of the circuit schematic diagram to ensure that every student is able to participate in the project according to the division of the labour. (3) Building and debugging the experimental circuits. The designed circuit should be built and debugged after 
the simulation and verification. The students should complete the project through the demonstration of the experimental plan, the preparation of the components, the welding and debugging of the circuits. (4) Measuring the experimental results and writing the experimental reports. After the debugging the experimental circuits, the experimental results should be measured and analysed, and the experimental reports ARE written and submitted. (5) Checking the experimental effect. The method of combining the teacher evaluation and student mutual evaluation is used to check and comprehensively evaluate the completion of experiments.

\subsection{Establish Diversified Experimental Assessment Method}

At present, the assessment of the electronic technology experimental courses is separated from the assessment of the corresponding theorical courses. The assessment results are mainly based on the experimental reports and attendance rates. Thus, the assessment standards are not high, and the teaching evaluation is formalized, and it is difficult to reflect the experimental level and practical capability of the students. Thus, it is impossible to accurately and comprehensively evaluate the engineering quality and practical ability of the students (Nkomo \& Ojating, 2018).

To comprehensively evaluate the engineering quality and practical ability of the students, it is necessary to establish a diversified evaluation method of the experimental course, which mainly includes the task analysis, scheme design, operation process, fault analysis, troubleshooting, result analysis, report writing, classroom performance, teamwork, and innovation practice, etc (Yang, 2020). The diversified assessments run through the whole process of the experimental assessment (before, during and after the assessment), which can give full play to the students' subjective initiative, stimulate the students' interest in participating in experiments, and promote the experimental teaching reform (Kuo et al., 2021). Before the assessment, the students need to collect the relevant information according to experimental tasks and requirements, review the basic circuits, design the experimental plan and experimental simulation. During the assessment, according to the experimental plan and simulation, the PCB production, circuit construction, operation and debugging, fault analysis and elimination, and result observation and analysis are carried out. After the assessment, according to the experimental process and results, the students should write the experimental reports, discuss the experimental results, make the experimental PPT, and carry out the experimental reports. Through a comprehensive evaluation of the whole process of the experiments conducted by the students, the engineering quality and practical capability of the students can be accurately evaluated (Tzacheva1 \& Easwaran, 2021).

Moreover, the implementation of a two-way assessment mechanism should be carried out, in addition to assessing the learning situation of the students, but also assessing the teaching situation of the teachers (Ozkan et al., 2019). It can not only give play to the students' subjective initiative, stimulate the students' enthusiasm and interest, but also can promote the teachers to improve and perfect the teaching methods and then further improve the teaching effect of the experimental courses.

\subsection{Optimize Knowledge Structure of Experiment Teachers}

Under the normal circumstances, the teachers of the theoretical course directly undertake the teaching of the corresponding experimental course, or the newly recruited young teachers undertake the teaching of the experimental course. This may be due to the teacher's lack of the teaching training of the specialized experimental course, or even the experience of the scientific research and engineering practice, which fails to meet the requirements of the teaching of the experimental course. In addition, the teachers generally determine the teaching tasks, contents and requirements themselves, which may lead to formalism and lack of the open and innovative projects of the experiments (Deng, 2016). 
To improve the effect and quality of the experimental teaching, the full-time experimental teachers with the actual engineering experience are needed, or the special pre-job training is needed for the experimental teachers. Thus, the experimental teachers should have the good engineering practice ability and high engineering literacy. The teachers of the experimental course should also actively engage in the scientific research and engineering projects and introduce the scientific research results into the experimental courses, which can cultivate the students' innovation capability, engineering awareness and practical capability (Forcael et al., 2021). In addition, the teacher of the experimental teaching should strengthen the mutual communication with the teacher of the theoretical teaching, pay the attention to the combination of the engineering practice and theoretical knowledge, which can build a high-quality and highquality teaching faculty of the electronic technology course (Brandhofer \& Miglbauer, 2020).

\section{Case Analysis}

Based on the above reform strategy, the teaching centre has established a complete set of the experimental teaching system of the electronic technology for the students. Table 1 shows the

Table 1. Reform detailed of the electronic technology experimental course

\begin{tabular}{|c|c|c|c|c|}
\hline Number & $\begin{array}{l}\text { Class } \\
\text { hours }\end{array}$ & $\begin{array}{c}\text { Operation } \\
\text { platform }\end{array}$ & Experiment content & Ability analysis \\
\hline \multirow{3}{*}{$\begin{array}{l}\text { Experiment } 1 \\
\text { (Circuit) }\end{array}$} & \multirow[b]{2}{*}{$\begin{array}{l}2 \text { hours } \\
\text { (In class) }\end{array}$} & \multirow[b]{2}{*}{ Hardware } & $\begin{array}{l}\text { Using of the experimental } \\
\text { platform and verification of } \\
\text { the Thevenin theorem }\end{array}$ & $\begin{array}{l}\text { Mastering the basic } \\
\text { knowledge points, and the } \\
\text { preliminary analysis and } \\
\text { problem-solving capability }\end{array}$ \\
\hline & & & $\begin{array}{l}\text { Using of the experimental } \\
\text { device and error } \\
\text { troubleshooting methods }\end{array}$ & $\begin{array}{c}\text { Basic experimental skills, } \\
\text { and the preliminary } \\
\text { analysis and ability to } \\
\text { solve the practical } \\
\text { problems }\end{array}$ \\
\hline & $\begin{array}{l}\text { Before } \\
\text { class }\end{array}$ & Software & $\begin{array}{l}\text { Analysis of the single- } \\
\text { phase bridge rectifier } \\
\text { circuit }\end{array}$ & $\begin{array}{l}\text { Ability to solve and } \\
\text { analyse the problems, and } \\
\text { the innovation ability, } \\
\text { research and learning } \\
\text { capability }\end{array}$ \\
\hline \multirow{3}{*}{$\begin{array}{l}\text { Experiment } 2 \\
\quad \text { (Analog } \\
\text { electronics) }\end{array}$} & \multirow{2}{*}{$\begin{array}{l}2 \text { hours } \\
\text { (In class) }\end{array}$} & \multirow[b]{2}{*}{ Hardware } & $\begin{array}{c}\text { Proportional and } \\
\text { summation circuit of the } \\
\text { integrated operational } \\
\text { amplifier }\end{array}$ & $\begin{array}{l}\text { Mastering the basic } \\
\text { knowledge points, and the } \\
\text { preliminary analysis and } \\
\text { problem-solving capability }\end{array}$ \\
\hline & & & $\begin{array}{l}\text { Using of the analog } \\
\text { learning machine and } \\
\text { multimeter, and the } \\
\text { troubleshooting methods }\end{array}$ & $\begin{array}{c}\text { Basic experimental skills, } \\
\text { and the preliminary } \\
\text { analysis and ability to } \\
\text { solve the practical } \\
\text { problems }\end{array}$ \\
\hline & $\begin{array}{l}\text { Before } \\
\text { class }\end{array}$ & Software & $\begin{array}{l}\text { Using of the operational } \\
\text { amplifier to generate the } \\
\text { square wave circuit with } \\
\text { the adjustable duty cycle }\end{array}$ & $\begin{array}{l}\text { Ability to solve and } \\
\text { analyse the problems, and } \\
\text { the innovation ability, } \\
\text { research and learning } \\
\text { capability }\end{array}$ \\
\hline $\begin{array}{l}\text { Experiment } 3 \\
\text { (Digital } \\
\text { electronics) }\end{array}$ & $\begin{array}{l}2 \text { hours } \\
\text { (In class) }\end{array}$ & Hardware & $\begin{array}{l}\text { Test of the gate circuit, and } \\
\text { the analysis of the } \\
\text { combinational logic circuit }\end{array}$ & $\begin{array}{l}\text { Mastering the basic } \\
\text { knowledge points, and the } \\
\text { preliminary analysis and } \\
\text { problem-solving capability }\end{array}$ \\
\hline
\end{tabular}


International Journal of Education (IJE) Vol.9, No.4, December 2021

\begin{tabular}{|c|c|c|c|c|}
\hline & & & $\begin{array}{l}\text { Master the use of the digital } \\
\text { circuit learning machine, } \\
\text { and the common error } \\
\text { troubleshooting methods }\end{array}$ & $\begin{array}{c}\text { Basic experimental skills, } \\
\text { and the preliminary } \\
\text { analysis and ability to } \\
\text { solve the practical } \\
\text { problems }\end{array}$ \\
\hline & $\begin{array}{c}\text { Before } \\
\text { class }\end{array}$ & Software & $\begin{array}{l}\text { Use the } 555 \text { timer to } \\
\text { generate the square wave } \\
\text { with the adjustable duty } \\
\text { cycle }\end{array}$ & $\begin{array}{l}\text { Ability to solve and } \\
\text { analyse the problems, and } \\
\text { the innovation ability, } \\
\text { research and learning } \\
\text { capability }\end{array}$ \\
\hline \multirow{2}{*}{$\begin{array}{c}\text { Experiment } 4 \\
\text { (Comprehensive } \\
\text { experiment) }\end{array}$} & $\begin{array}{l}4 \text { hours } \\
\text { (In class) }\end{array}$ & Hardware & \multirow{2}{*}{$\begin{array}{l}\text { Simulation and control } \\
\text { realization of the working } \\
\text { principle of three-phase fully } \\
\text { controlled rectifier circuit }\end{array}$} & \multirow{2}{*}{$\begin{array}{l}\text { Comprehensive analysis of } \\
\text { the problem-solving } \\
\text { ability, research learning } \\
\text { ability, innovation ability, } \\
\text { and engineering capability }\end{array}$} \\
\hline & $\begin{array}{c}\text { Before } \\
\text { class }\end{array}$ & Software & & \\
\hline
\end{tabular}

specific experimental content and operation modes. There is a total of ten hours of the electronic technology experimental course, which can be divided into four experiments to carry out.

In the experiment 1 , the experiment content is belonging to the circuit course. The classroom experiment is the use of the experimental platform of the electronic technology, and the analysis of the troubleshooting steps and the verification of the Thevenin theorem. The purpose is to train the students to use the hardware platform to analyse and verify the experimental skills of the basic experimental theories, and to deepen the mastery and understanding of the Thevenin theorem. The pre-class experiment is the analysis of the single-phase bridge rectifier circuit, whose operation is completed on the software platform. The students can arbitrarily analyse the influence of various parameters in the main circuit on the circuit performance on the software platform, which will help the students obtain the capability of solving problems and train the innovation ability. The proteus software platform provides the schematic diagram of a singlephase bridge rectifier circuit, which needs the following requirements. First, the basic working principle of the main circuit is analysed. Second, as the load is the resistive load, capacitive load, and resistive-capacitive load, the working process of the circuit is analysed. Finally, the proteus software is used to verify the working state of the circuit analysed in step two by the simulation.

In the experiment 2 , the experiment content is belonging to the analog electronics course. The classroom experiments include the use of the analog learning machines and multimeters, the analysis and introduction of the error troubleshooting steps and methods in the experimental process, and the integrated operational amplifier ratio and summation circuit experiments. The pre-class experiment is the design and simulation of a square wave generating circuit with an adjustable duty cycle using an operational amplifier. The proteus software platform provides a schematic diagram of a square wave using an integrated operational amplifier, which needs the following requirements. First, the square wave generating circuit is analysed. Second, the circuit parameters are designed to generate a square wave signal with a duty cycle of 0.5 and a square wave signal with a duty cycle of 0.4. Finally, according to the design parameters, the Proteus software is used to simulate and verify the design correctness.

In the experiment 3, the experiment content is belonging to the digital electronics course. The classroom experiments include the use of the digital circuit learning machines, common error troubleshooting methods in the digital circuits, gate circuit testing and combinational logic circuit analysis. The pre-class experiment is the design and simulation of a square wave signal circuit which applies a 555 timer to form a duty cycle. The proteus software platform provides a schematic diagram of a square wave circuit applying the 555 timers, which needs the following requirements. First, the principle of the square wave generating circuit with a fixed duty cycle is 
analysed, which is generated by using the 555 timers, and then the proteus software is used to simulate and design the parameters. Second, a square wave generating circuit with an adjustable duty cycle is designed, and then its working principle is analysed and the simulation verification is carried out by the proteus software.

The experiment 4 is a comprehensive experiment. The content of the comprehensive experiment is concatenated with the pre-class content of the first three experiments to obtain a simple comprehensive experiment topic, that is to use a 555 timer to generate a square wave pulse with the adjustable duty cycle. The square wave pulse triggers the single-phase and bridge-type controllable rectifier circuit composed of the thyristors to produce output the waveforms with the different requirements. The pre-class experiment requires that the first three experiment contents are combined to complete the design of the whole content of the comprehensive experiment, as well as the software simulation verification. The class experiments are completed in the laboratory room. The teacher should check the results of the student's experiment, solve the issues met by the student in the entire software experiment, and then evaluate the student's defence. At the same time, the students organize the design process of the comprehensive experiments into an experimental report and analyse and summarize the experimental results.

The first three experimental classes are the basis for the last comprehensive experiments. The classroom experiments in the first three classes has cultivated the students' basic experimental skills and the capability to solve the issues met in the analysis experiment. The content of the simulated platform experiments has deepened the students' mastery of each knowledge point of the experiment 4 (the comprehensive experiment), and the students' understanding of the knowledge points. The comprehensive experiment allows the students to complete a simple engineering project in a limited time. The organic combination of the four experimental courses and the effective use of the network platform have not only cultivated the students' basic experimental skills and then deepened their understanding of the basic knowledge, but also allowed the students to have a simple and systematic engineering practice and learning experience in a limited time, cultivate the students' ability to simply design and implement the engineering experiments, and master the basic innovative methods, which have an attitude and awareness of pursuing the innovation and suitable for the requirements of the development of the "new engineering".

\section{EFFECTS AND REFLECTION}

At present, the experimental teaching reform of the electronic technology is being actively carried out. The experimental courses of the analog electronic technology and digital electronic technology have been carried out in the fall semester of 2020 and the spring semester of 2021, and the circuit experimental course is being conducted in the fall semester of 2021 .

In the whole process of the teaching reform, the teachers choose the unique and innovative design of the electronic technology experiment is a highlight. The innovative design experiment process not only deepens the students' understanding of the basic course knowledge of the electronic technology, but more importantly, it would provide the students with a complete comprehensive training on the application of the electronic technology knowledge, which lays a good foundation for the students to apply the electronic knowledge in their professional field and is also well received by the students and leaders.

The students believe that this innovative experiment with a design nature breaks the framework of the original model of the experimental teaching. During the experiments, the student has experienced the layers of in-depth research, such as the "task selection-preparatory discussionsubmission of the schemes-independent experiments-summary and defence". This link allows the 
students to learn the capability to comprehensively apply all relevant knowledge in the process of the problem solving, gives the students many opportunities to contact the engineering analysis, and cultivates the certain engineering design capabilities and literacy. Focusing on the problems, the group discussions in the small classes can guide the students to think deeply about how to solve problems and stimulate the students' initiative in the learning, which has also been widely recognized by the students and university.

Of course, the teaching links such as the group discussion and innovative design are completed by the group members, which has a good effect on the students with active learning awareness. However, for the students with a weak sense of the active learning, there is a phenomenon of the being confused. The situation of the free-riding and soy sauce exists objectively, and it is very difficult for the course assessment results to be absolutely fair and just. In addition, the practical topic training of the course uses the laboratory and software programming, it is inevitable that there will be the mutual duplication. This is also an issue that must be taken in account and solved in the future experimental teaching process of the electronic technology.

\section{Conclusion}

The construction and development of the "new engineering" is a process of the long-term exploration and practice. It is based on the present, face to the future, explore in depth with a dynamic and developmental thinking, and push forward with the perseverance. Based on the innovative concept of the "new engineering", the college's engineering education should incorporate the engineering practice ability training and comprehensive professional quality training into the experimental teaching, which is of great significance for improving the quality of the higher engineering education.

This paper presents the study on the experimental teaching reform of the electronic technology course adapted to the development of the "new engineering", and then actively targets the construction of the "new engineering" disciplines, from rebuilding the experimental teaching systems, updating the experimental teaching contents, reforming the experimental teaching methods, innovating and organizing the experimental teaching processes, and establishing the evaluation methods of the diversified experiments and optimization of the knowledge structure of the experimental teachers were discussed in depth, and the corresponding reform measures were put forward. The teachers and students felt the shock brought by the proposed teaching reform. The teachers have seen the unprecedented enthusiasm of the students for the learning and scientific research, and they have also been deeply infected to invest more energy in the research and teaching. The students also find that this method can learn the new knowledge faster and more confidently, and then understand the general methods of the scientific research and touch the frontiers of disciplines. It can not only promote the students' experimental skills in an allround way, cultivate the students' engineering awareness and the ability to analyse and solve the engineering problems, but also promote the teachers to continuously improve the experimental teaching mode and improve their own engineering practice capabilities, which is helpful to achieve the goal of cultivating the high-quality engineering and technology talents.

\section{ACKNOWLEDGEMENTS}

All authors would like to thank the editors and reviewers for their very competent comments and helpful suggestions to improve this paper. This work has been co-supported by the 2020 Undergraduate Teaching Reform Research Project of Sun Yat-Sen University under Grant Sun Yat-Sen University Academic Affairs [2020] No.72, by the 2020 Undergraduate Competition Funding Project of Sun Yat-Sen University under Grant Sun Yat-sen University Academic 
International Journal of Education (IJE) Vol.9, No.4, December 2021

Affairs [2020] No.231, by the National Natural Science Foundation of China under Grant 61801510, by the Guangdong Basic and Applied Basic Research Foundation under Grants 2021A1515010768 and 2214050002344, and by the National Science Foundation of Hubei Province under Grant 2019CFB263. Guoqian Wang and Kai Xie are the corresponding authors.

\section{CONFLICT OF INTEREST}

All authors confirmed that there is no conflict of interest involve with any parties in this work.

\section{REFERENCES}

[1] Barnes, C.D., Kohler-Evans, P., \& Wingfield, R.A., (2020) “Are we effectively teaching today's college student?”, International Journal of Education, Vol.8, No.4, pp 45-54.

[2] Brandhofer, G., \& Miglbauer, M., (2020) "Digital competences for teachers - the Digi.Kompp model in an international comparison and in the practice of Austrian teacher training", International Journal of Education, Vol.8, No.4, pp 55-69.

[3] Deng, W.T., (2016) "Reengineering the function of university laboratory under the background of stimulating university students' innovation and entrepreneurship", Higher Education Exploration, Vol.1, pp 95-98.

[4] Duarte, A.J., et al., (2020) "Engineering education for sustainable development: The European project semester approach", IEEE Transactions on Education, Vol. 63, No.2, pp 108-117.

[5] Forcael, E., Garcés, G., \& Orozco, F., (2021) "Relationship between professional competencies required by engineering students according to ABET and CDIO and teaching-learning techniques", IEEE Transactions on Education, doi: 10.1109/TE.2021.3086766. (early access).

[6] Geng, X.J., Shen, L., Deng Y.X., \& Lin, L., (2020) "Discussion on the talent training of universities with industry characteristics from the perspective of courses", International Journal of Education, Vol.8, No.3, pp 11-18.

[7] Geng, X., (2020) "Discussion on large-scale online education practices amid the novel coronavirus outbreak", International Journal of Education, Vol.8, No.4, pp 13-18.

[8] Hadek, A., Chaibate, H., Bakkali, S., \& Ajana, S., (2019) "Sipoc model in moroccan engineering education context: lean approach", International Journal of Education, Vol.7, No.1, pp 47-61.

[9] Kaloostian, D., \& Chhetri, N., (2021) "Information and communication technology (ICT) inequities: a comparative literature review of education in the United States and Liberia”, International Journal of Education, Vol.9, No.2, pp 49-68.

[10] Kittur, J., (2020) "Measuring the programming self-efficacy of electrical and electronics engineering students", IEEE Transactions on Education, Vol.63, No.3, pp 216-223.

[11] Kuo, H.C., Yang, Y.T.C., Chen, J.S., Hou, T.W., and Ho, M.T., (2021) "The impact of design thinking PBL robot course on college students' learning motivation and creative thinking," IEEE Transactions on Education, doi: 10.1109/TE.2021.3098295. (early access).

[12] Lalos, C., \& Skarpa, I., (2020) "Educational digital games as learning tools: microsoft kodu's case", International Journal of Education, Vol.8, No.3, pp 1-10.

[13] Leung, J.K.L., Chu, S.K.W., Pong, T.C., Ng, D.T.K., \& Qiao, S., (2021) "Developing a framework for blended design-based learning in a first-year multidisciplinary design course", IEEE Transactions on Education, doi: 10.1109/TE.2021.3112852. (early access).

[14] Li, Z.L., Liao, R.J., \& Dong, L.Y., (2018) "Specialty construction for the emerging engineering education: connotation, formation, path and training mode", Research in Higher Education of Engineering, Vol.2, pp 20-24,

[15] Lin, J., (2017) "The construction of China's new engineering disciplines for the future", Tsinghua Journal of Education, Vol.38, No.2, pp 26-35.

[16] Ministry of Education, (2017a) "Fudan consensus: The construction of new engineering", Research in Higher Education of Engineering, Vol.1, pp10-11.

[17] Ministry of Education, (2017b) "Action line of new engineering construction (Tianda Action)", Research in Higher Education of Engineering, Vol.2, pp 24-25.

[18] Ministry of Education, (2017c) "Guide of new engineering construction (Beijing Guide)", Research in Higher Education of Engineering, Vol.4, pp 20-21. 
[19] Nkomo, N.N., \& Ojating, H., (2018). Effective coverage of learning domains in students assessment by lecturers of cross river university of technology Calabar Nigeria", International Journal of Education, Vol.6, No.4, pp 23-29.

[20] Ntinda1, K., \& Ngozwana, N., (2021) "International higher education students and educators psychological experiences of Covid-19 in an emerging country", International Journal of Education, Vol.9, No.2, pp 33-48.

[21] Ozkan, D. S., Mcnair, L.D., \& Bairaktarova, D., (2019) “Teacher learner, learner teacher: parallels and dissonance in an interdisciplinary design education minor", IEEE Transactions on Education, Vol.62, No.3, pp 226-235.

[22] Passadelli, A.S., \& Klonari, A., (2021) "The effectiveness of an ICT based teaching scenario of tsunami on students' learning: a case study", International Journal of Education, Vol.9, No.1, pp 1323.

[23] Rohde, J., et al., (2019) "Design experiences, engineering identity, and belongingness in early career electrical and computer engineering students," IEEE Transactions on Education, Vol.62, No.3, pp165-172.

[24] Shang, Z.J., Deng, Q.T., Li, X.B., \& Ruan, M., (2019) "Design of experimental teaching reform on basic disciplines of science and engineering based on idea of "New engineering", Experimental Technology and Management, Vol.36, No.9, pp149-150.

[25] Tzacheva1, A., \& Easwaran, A., (2021) "Emotion detection and opinion mining from student comments for teaching innovation assessment", International Journal of Education, Vol.9, No.2, pp 21-32.

[26] Wang, W.D., Yuan, X.Q., Shi, Y.K., \& Zhao, N., (2020) "Exploration on reform of experimental teaching mode of "electrical engineering" under the background of new engineering", University Education, Vol.2, pp 23-26.

[27] Wen, Z.R., (2021) "Packaging's visual three-dimensional presentation and experience with virtual simulation", In International Conference on Computing and Data Science, Vancouver Canada, 2021, pp 1-6.

[28] Xie, H.T., Lang, K., Jiang, X.Q., Chen, K.P., \& Wang, G.Q., (2021) "Research on teaching reform of electronic technology experiment adapted to development of emerging engineering", Journal of Higher Education, Vol.35, No.1, pp 1-6.

[29] Yang, Y., (2020) "Research on reform of electronic technology experiment teaching based on professional certification of engineering education", Industry and Information Technology Education, Vol.1, pp 84-89.

[30] Yuan, Y.C., Lv, N.L., Lai, L.J., \& Yin, R.X., (2019) "Scientific design and process management scheme of experimental teaching for engineering education", Experimental Technology and Management, Vol.36, No.1, pp 192-198.

\section{AUTHORS}

Hongtu Xie was born in 1986 and received the B.S. degree in the electronic information engineering from the Hunan University (HNU), Changsha, P.R. China, in 2008, received the M.S. degree in the electronic science and technology from the National University of Defense Technology (NUDT), Changsha, P.R. China, in 2010 and received the Ph.D. degree in the information and communication engineering from the NUDT, Changsha, P.R. China, in 2015. He is currently an Associate professor and a M.S. Supervisor with the School of Electronics and Communication Engineering, Sun

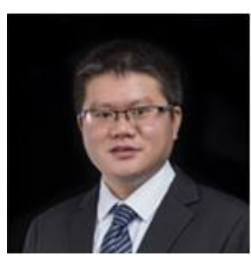
Yat-sen University (SYSU), Guangzhou, P.R. China, and the judge's experts of the National natural Science Foundation of China and the Guangdong Basic and Applied Basic Research Foundation. His research filed is the electronic technology, high-resolution SAR imaging, and target detection and recognition. He received the Excellent Doctoral Dissertation of the Chinese People's Liberation Army Award for his Ph.D. dissertation in 2018, and the Third Prize of Teaching Competition for the Young Teacher of the School of Electronics and Communication Engineering in 2020. 
International Journal of Education (IJE) Vol.9, No.4, December 2021 